\title{
COMPARISON OF CUMULATIVE DISEASE DAMAGE IN SMOKERS VS. NON-SMOKERS SYSTEMIC LUPUS ERYTHEMATOSUS PATIENTS THROUGH THE SLICC/ACR INDEX
}

Kamilla de Bessa Jorge ${ }^{1, \star}$, Nelzi Ferreira de Queiroz Júnior ${ }^{1}$, Arturo Vicenzo Dassoler Puff ${ }^{1}$, Tiago Takahiro Hioki ${ }^{1}$, Thiago Alberto Gomes Dos Santos ${ }^{1}$, Thelma Larocca Skare ${ }^{1}$

1.Hospital Universitário Evangélico Mackenzie, Curitiba (PR), Brazil.

*Corresponding author: kamillabessajorge@gmail.com

\section{BACKGROUND}

Systemic lupus erythematosus (SLE) is a multisystemic, chronic inflammatory disease of unknown cause and autoimmune nature. Tobacco has effects on SLE disease activity, since it has several chemical factors that affect cell growth. Cigarette chemicals are metabolized, generating free radicals that interact with DNA and cause oxidative damage to nuclear constituents. It also modifies the response to drug treatment: antimalarial and belimumab are medications that suffers influence of tobacco. The aim of this study was to compare the cumulative disease damage in SLE patients with and without tobacco exposure.

\section{METHODS}

Retrospective study of 100 SLE patients: 50 smokers vs. 50 nonsmokers from a single rheumatology center. Collected information included epidemiological, clinical and laboratory data to calculate cumulative damage through the Systemic Lupus International Collaborating Clinics /American College of Rheumatology (SLICC/ACR) damage index.

\section{RESULTS}

Smokers and nonsmokers patients were paired for gender, age and disease duration. No differences between the two groups were observed in the total result of SLICC/ACR damage index. However, when the different domains were studied, smokers had more ocular and cardiovascular damage than nonsmokers (both with $\mathrm{p}-0.02$ ).

\section{CONCLUSION}

Systemic lupus erythematosus patients that smoke have more cumulative damage including the cardiovascular and ocular areas.

\section{KEYWORDS}

Systemic lupus erythematosus, Tobacco, Cumulative damage. 